\title{
Creep Strain and Strain Rate Response of 2219 Al Alloy at High Stress Levels
}

\author{
Karen M. B. Taminger, John A. Wagner, and W. Barry Lisagor \\ NASA Langley Research Center, M. S. 188A, Hampton, VA, 23681-2199 USA
}

Keywords: time-dependent deformation, creep strain, strain rate response, 2219 aluminum, prestrain, International Space Station

\begin{abstract}
As a result of high localized plastic deformation experienced during proof testing in an International Space Station connecting module, a study was undertaken to determine the deformation response of a 2219-T851 roll forging. After prestraining 2219-T851 Al specimens to simulate strains observed during the proof testing, creep tests were conducted in the temperature range from ambient temperature to $107^{\circ} \mathrm{C}\left(225^{\circ} \mathrm{F}\right)$ at stress levels approaching the ultimate tensile strength of 2219-T851 Al. Strain-time histories and strain rate responses were examined. The strain rate response was extremely high initially, but decayed rapidly, spanning as much as five orders of magnitude during primary creep. Select specimens were subjected to incremental step loading and exhibited initial creep rates of similar magnitude for each load step. Although the creep rates decreased quickly at all loads, the creep rates dropped faster and reached lower strain rate levels for lower applied loads. The initial creep rate and creep rate decay associated with primary creep were similar for specimens with and without prestrain; however, prestraining (strain hardening) the specimens, as in the aforementioned proof test, resulted in significantly longer creep life.
\end{abstract}

\section{Introduction}

Node 1 (also called "Unity") is a connecting passageway to living and working areas of the International Space Station (ISS), Fig. 1. In addition, Node 1 has six hatches that serve as docking ports for other modules. During required proof testing to twice the internal operating pressure, localized yielding occurred in the 2219-T851 aluminum roll forging at a high stress region of the radial port wall gusset (photo inset on Fig. 1) prior to reaching the proof pressure. Due to the combination of yielding during the proof test and the high localized operating stresses at the gusset, there was concern that time dependent plastic deformation could result in a reduction of the useful life of Node 1. This investigation was undertaken to characterize the time dependent

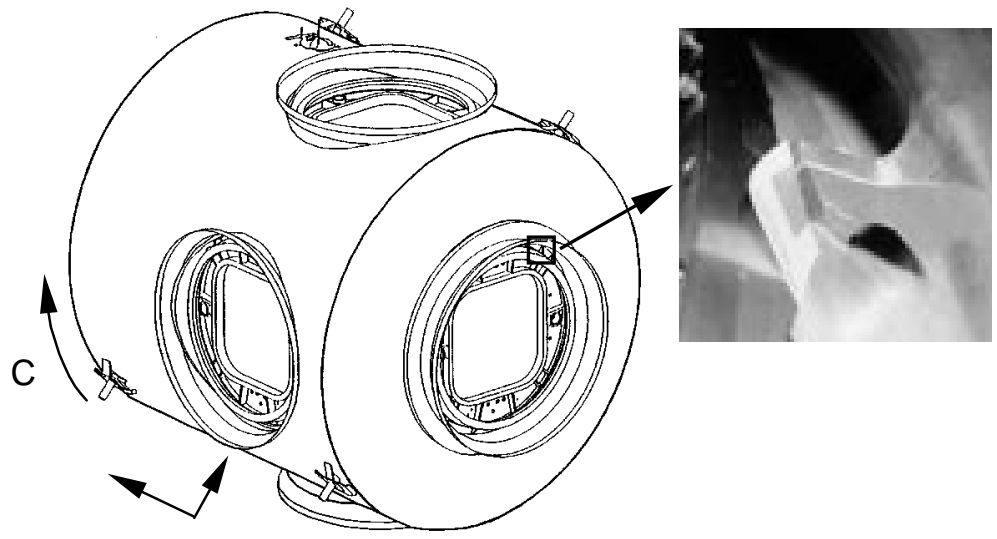

Figure 1. Schematic of Node 1 for the International Space Station, with inset photo of gusset region. Coordinate system: $\mathrm{A}=$ axial, $\mathrm{R}=$ radial, $\mathrm{C}=$ circumferential. 
deformation behavior of the 2219-T851 roll forging. The creep behavior for high stress / moderate temperature conditions was characterized, and the results were used to develop a constitutive equation (discussed in detail in reference [1]) to predict long term behavior with short term tests, thus enabling the determination of the "creep life" of the gussets while on orbit.

\section{Materials and Experimental Procedures}

The material tested was a roll forging of aluminum alloy 2219-T851 (Al-6.4 Cu-0.3 Mn0.2 Fe-0.1 V-0.1 Zr-0.07 Ti-0.06 Si) which was produced as a demonstration part for the actual Node 1 flight hardware. The roll-forged ring was approximately $4.27 \mathrm{~m}(14 \mathrm{ft})$ in diameter by $0.36 \mathrm{~m}$ (14 in.) in height by $0.13 \mathrm{~m}(5 \mathrm{in}$.) thick with a typical microstructure shown in Fig. 2.

Specimens were machined as $1.3 \mathrm{~cm}(0.5$ in.) diameter threaded-end rounds (per ASTM E8 [2]) with the longitudinal axis inclined at an angle of $66^{\circ}$ with respect to the A direction in the AR plane (Fig. 2) to be aligned with the orientation of the gussets where yielding originated during the proof test. Tensile tests were conducted in the -T851 condition at various elevated temperatures to characterize the 2219T851 tensile properties over the temperature

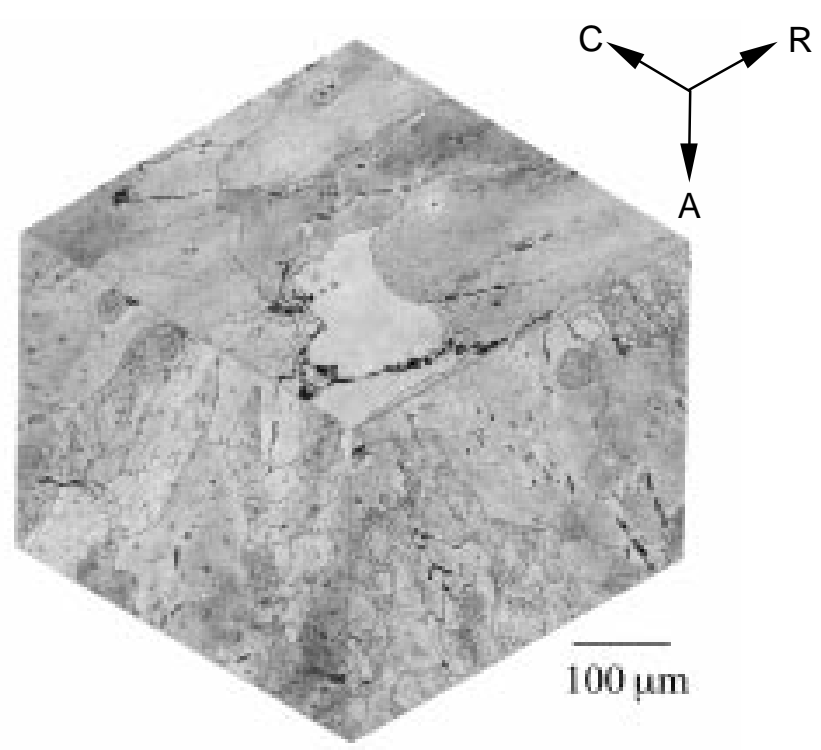

Figure 2. Typical microstructure of 2219-T851 roll forging. range for the creep tests. Tensile tests were conducted per ASTM E8 [2] with a constant stroke rate of $1.3 \mathrm{~mm} / \mathrm{min}(0.05 \mathrm{in} / \mathrm{min})$, using back-to-back $2.54 \mathrm{~cm}$ (1.0 in.) axial extensometers to measure strain.

Creep tests were conducted using constant applied load. Strains were measured using back-toback $2.54 \mathrm{~cm}$ (1.0 in.) axial extensometers, which were calibrated at the test temperature prior to the start of each test. The stress and temperature ranges were selected to be representative of the service conditions for the ISS during proof testing and on orbit. The design allowable stress for the ISS on orbit is $265 \mathrm{MPa}$ (38 ksi), and the Node 1 module experienced localized stresses possibly as high as $349 \mathrm{MPa}(50 \mathrm{ksi})$ during proof testing. [1] Therefore, the stress levels selected for creep testing were $224,265,293,321,342$, and $363 \mathrm{MPa}(32,38,42,46,49$, and $52 \mathrm{ksi})$ which represented values of $60,70,80,85,90$, and $98 \%$ of the room temperature ultimate tensile strength respectively. The external temperature of Node 1 on orbit is anticipated to be from -51 to $+56^{\circ} \mathrm{C}$ $\left(-60\right.$ to $\left.+132^{\circ} \mathrm{F}\right)$. [1] Creep test temperatures were increased slightly to accelerate testing, but were restricted to ensure that thermally activated creep deformation mechanisms were not introduced, which would change the anticipated creep mechanisms from those expected under typical ISS service conditions. Test temperatures selected were $22,56,79$, and $107^{\circ} \mathrm{C}(72,132,175$, and $225^{\circ} \mathrm{F}$ ). Select combinations of the above temperatures and stresses were used for creep testing. In addition, tests were performed by incrementally increasing the load on the specimen and holding that load for times greater than 100 hours at each step.

Most creep specimens were strained at room temperature prior to creep testing to simulate the actual condition in Node 1 after localized yielding occurred during the proof test. For the purposes of this report, this operation will be referred to as "prestraining." To prestrain, the specimens were loaded in a hydraulic tensile test machine using constant stroke rate of $1.3 \mathrm{~mm} / \mathrm{min}(0.05 \mathrm{in} / \mathrm{min})$ until the strain level reached 1.0\% (approximately $349 \mathrm{MPa}(50 \mathrm{ksi})$ stress). The specimen was then held at constant load, allowing the specimen to deform until the strain reached $1.5 \%$ before unloading to simulate the strain history in the gusset observed during the proof test. This prestraining operation resulted in approximately $0.9 \%$ residual plastic strain in the specimen after 
unloading the specimen. Control specimens were not prestrained and subjected to similar creep test conditions (temperatures and stresses) to compare the creep response of the 2219-T851 with and without prestrain.

\section{Results \& Discussion}

Tensile properties of roll forged 2219-T851 in the as-received (no prestrain) condition for the $66^{\circ}$ orientation are shown in Table 1. Although these properties are somewhat lower than other published values [3], it should be noted that the tensile axis was $66^{\circ}$ to the A direction, and the specimens were machined from the same lot of material used to fabricate actual Node 1 hardware.

\begin{tabular}{|c|c|c|c|c|}
\hline $\begin{array}{c}\text { Temperature, } \\
{ }^{\circ} \mathrm{C}\left({ }^{\circ} \mathrm{F}\right)\end{array}$ & $\begin{array}{c}\text { Yield Strength, } \\
\mathrm{MPa}(\mathrm{ksi})\end{array}$ & $\begin{array}{c}\text { Ultimate Strength, } \\
\mathrm{MPa}(\mathrm{ksi})\end{array}$ & $\begin{array}{c}\text { Plastic Strain, } \\
\%\end{array}$ & $\begin{array}{c}\text { Total Strain, } \\
\%\end{array}$ \\
\hline $22(72)$ & $331(47.4)$ & $379(54.3)$ & 1.6 & 2.1 \\
\hline $56(132)$ & $316(45.3)$ & $373(53.4)$ & 2.3 & 2.8 \\
\hline $79(175)$ & $311(44.5)$ & $369(52.8)$ & 3.1 & 3.7 \\
\hline $107(225)$ & $300(43.0)$ & $348(49.8)$ & 3.3 & 3.9 \\
\hline
\end{tabular}

Table 1. Tensile properties of roll forged 2219-T851 (66 orientation) at different test temperatures.

A summary of data from all creep tests performed is shown in Table 2. Fig. 3 shows the straintime history (Fig. 3a) and the corresponding strain rate response (Fig. 3b) for four stress levels at $56^{\circ} \mathrm{C}\left(132^{\circ} \mathrm{F}\right)$. All specimens were prestrained to $1.5 \%$ at room temperature before creep testing as described previously. The total strain shown includes elastic strain from loading the creep tests plus

\begin{tabular}{|c|c|c|c|c|c|c|}
\hline \multirow[t]{2}{*}{$\begin{array}{l}\text { Temp., } \\
{ }^{\circ} \mathrm{C}\left({ }^{\circ} \mathrm{F}\right)\end{array}$} & \multirow[t]{2}{*}{$\begin{array}{c}\text { Stress, } \\
\mathrm{MPa}(\mathrm{ksi})\end{array}$} & \multirow[t]{2}{*}{$\begin{array}{c}\text { Time, } \\
\text { hrs }\end{array}$} & \multirow{2}{*}{$\begin{array}{c}\text { Total } \\
\text { Strain, } \\
\%\end{array}$} & \multicolumn{2}{|c|}{$\begin{array}{c}\text { Primary Creep Rate, } \\
\text { microstrain / hr }\end{array}$} & \multirow[t]{2}{*}{$\begin{array}{c}\text { Stop / } \\
\text { Rupture }\end{array}$} \\
\hline & & & & start & end & \\
\hline $22(72)$ & $\begin{array}{c}363(52) \\
\text { no prestrain }\end{array}$ & 0.5 & 2.4 & 310,000 & 2,500 & rupture \\
\hline $22(72)$ & $363(52)$ & 71 & 3.1 & 510,000 & 40 & rupture \\
\hline $22(72)$ & $\begin{array}{l}224(32) \\
265(38) \\
293(42) \\
342(49) \\
363(52)\end{array}$ & $\begin{array}{c}193 \\
217 \\
237 \\
1,102 \\
234\end{array}$ & $\begin{array}{c}1.29 \\
1.35 \\
1.42 \\
1.9 \\
3.6\end{array}$ & $\begin{array}{c}6,600 \\
370 \\
950 \\
3,500 \\
94,000\end{array}$ & $\begin{array}{c}0.27 \\
0.38 \\
0.43 \\
1.8 \\
29\end{array}$ & $\begin{array}{l}\text { step to } 265 \mathrm{MPa} \\
\text { step to } 293 \mathrm{MPa} \\
\text { step to } 342 \mathrm{MPa} \\
\text { step to } 363 \mathrm{MPa} \\
\quad \text { rupture }\end{array}$ \\
\hline $56(132)$ & $265(38)$ & 10,077 & 1.5 & 9,300 & 0.07 & stop \\
\hline $56(132)$ & $293(42)$ & 1,270 & 1.7 & 28,000 & 0.61 & stop \\
\hline $56(132)$ & $321(46)$ & 4,480 & 3.9 & 34,000 & 3.0 & rupture \\
\hline $56(132)$ & $342(49)$ & 117 & 3.1 & 73,000 & 56 & rupture \\
\hline $79(175)$ & $265(38)$ & 500 & 1.6 & 48,000 & 1.1 & stop \\
\hline $107(225)$ & $\begin{array}{c}265(38) \\
2.0 \% \text { prestrain }\end{array}$ & 271 & 3.7 & 52,000 & 42 & rupture \\
\hline
\end{tabular}

Table 2. Creep data summary for $2219-\mathrm{T} 851\left(66^{\circ}\right.$ orientation) with $1.5 \%$ prestrain except as noted.

residual strain from the prestraining. Tests conducted at 265 and $293 \mathrm{MPa}$ (38 and $42 \mathrm{ksi}$ ) were terminated prior to rupture because the specimens exhibited negligible amounts of creep. Specimens tested at 321 and $342 \mathrm{MPa}$ (46 and $49 \mathrm{ksi}$ ) failed by creep rupture, noted by (R) on Fig. 3. Of these four stress levels, only the test at $321 \mathrm{MPa}(46 \mathrm{ksi})$ exhibited any appreciable steadystate or tertiary creep over the durations tested. The continuously decreasing creep rates in Fig. $3 \mathrm{~b}$ demonstrate that in this high stress-moderate temperature regime, creep deformation is dominated by primary creep. Previous work at NASA Langley on primary creep in aluminum alloys [4] shows that such behavior is readily described by the following power law equation: 


$$
\varepsilon=a \cdot t^{b}+c
$$

where $\varepsilon$ is the creep strain, $t$ is the time, and $a, b$, and $c$ are empirically determined constants. Data in Fig. 3a at $293 \mathrm{MPa}$ (42 ksi) show the experimental data as points with the curve fit superimposed to demonstrate the fit of Eq. 1 to the primary portion of the experimental data. The instantaneous creep rate can be calculated from the first derivative of the power law in Eq. 1:

$$
\dot{\varepsilon}=a \cdot b \cdot t^{(b-1)}
$$

where $\dot{\varepsilon}$ is the creep rate, and $t, a$, and $b$ are the same as in Eq. 1. The strain rate response based upon calculated strain rates using Eq. 2 for these four test conditions is shown in Fig. 3b. Since Eq. 2 can only be used to calculate primary creep rates, the instantaneous creep rate as determined by $\Delta \varepsilon / \Delta t$ on a point-to-point basis is also shown for the $321 \mathrm{MPa}$ (46 ksi) test as black triangles in Fig. $3 \mathrm{~b}$ to show the steady-state and tertiary creep rates. The good agreement between the strain rates calculated from Eq. 2 and the point-to-point data for the primary portion of the $321 \mathrm{MPa}$ (46 ksi) test demonstrates that Eq. 1 is an appropriate functional form to model primary creep in these tests. At all stress levels, the specimens exhibited high initial creep strain rates, on the order of $10^{5} \mu \varepsilon / \mathrm{hr}$. Higher applied stress levels corresponded to slightly higher initial creep strain rates. These high initial creep rates dropped precipitously, covering as much as five orders of magnitude within the first several hours of the test. The wide range of creep rates observed over an extended period of time suggests slow dislocation response to the applied stress.
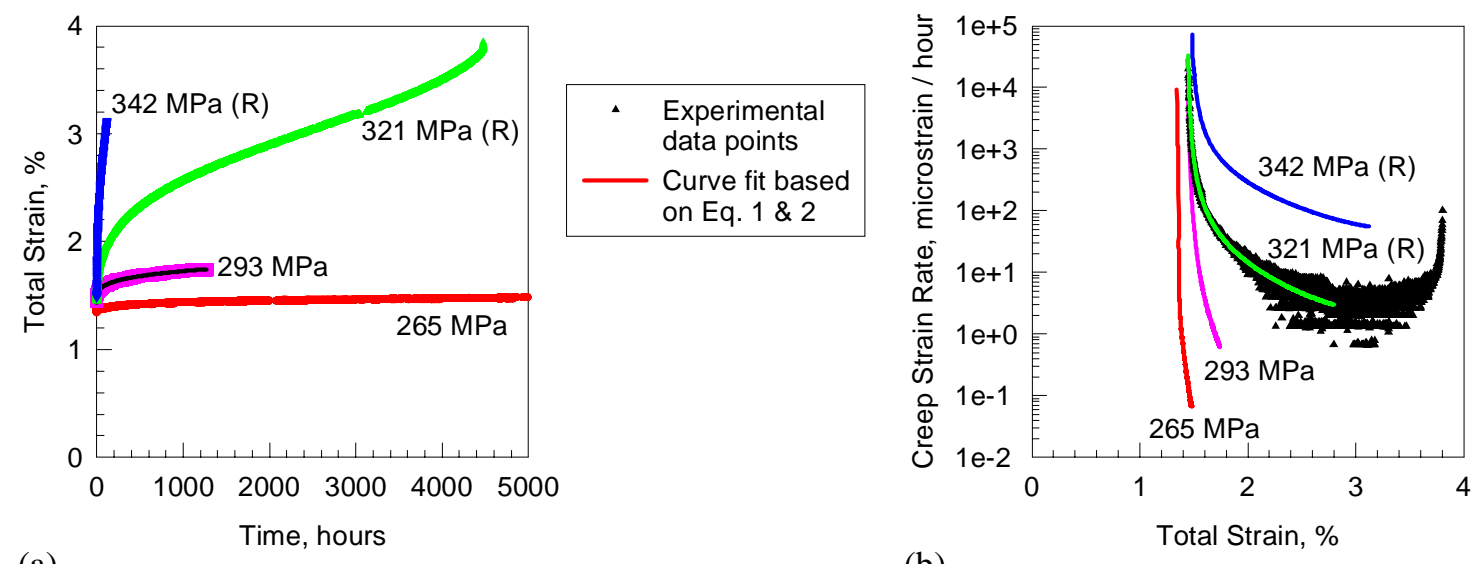

(a)

(b)

Figure 3. (a) Experimental creep strain data and (b) calculated creep strain rate data (based on Eq. 2) on $2219-\mathrm{T} 851$ at $56^{\circ} \mathrm{C}\left(132^{\circ} \mathrm{F}\right)$ after $1.5 \%$ prestrain.

Fig. 4 shows creep strain and strain rate data from a test that was step loaded at room temperature. Data shown for this specimen includes the $1.5 \%$ prestrain operation, followed by five incremental load steps, each step at a higher load level than the preceding step. (Specific stresses and times for the sequence of steps are shown in Table 2.) As with the data from Fig. 3 at $56^{\circ} \mathrm{C}$ $\left(132^{\circ} \mathrm{F}\right)$, each higher incremental step demonstrated higher creep strains and higher creep strain rates. At each increment, the strain rate returns to extremely high rates, then decays rapidly. There appears to be a correlation between the creep rate response and the applied stress: the higher the applied stress, the slower the decay in the creep rate, suggesting the higher applied stresses are sufficient to maintain dislocation mobility, but the lower stresses approach a threshold where dislocation mobility is low.

Fig. 5 shows the creep behavior of 2219-T851 over a range of temperatures at the ISS design stress of $265 \mathrm{MPa}$ (38 ksi). Again, all data shown was prestrained to $1.5 \%$ at room temperature prior to creep testing. In Fig. 5b, the instantaneous strain rate, as calculated on a point-to-point basis for the $107^{\circ} \mathrm{C}\left(225^{\circ} \mathrm{F}\right)$ test, is included as black triangles to show the steady-state and tertiary creep rates. For all data in the primary creep regime, strain rate curves in Fig. 5b are based upon 

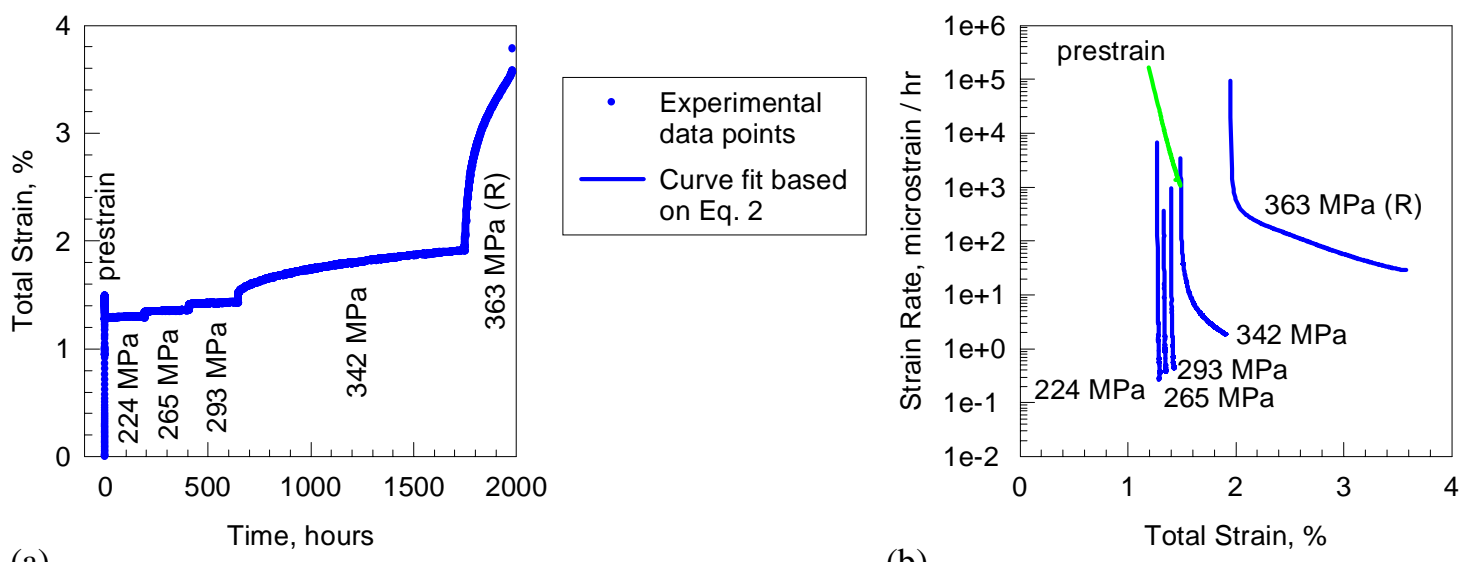

(a)

(b)

Figure 4. (a) Experimental creep strain data and (b) calculated creep strain rate data (based on Eq. 2) on $2219-\mathrm{T} 851$ at $22^{\circ} \mathrm{C}\left(72^{\circ} \mathrm{F}\right)$ for step loaded specimen with $1.5 \%$ prestrain.

Eq. 2. As expected, the higher temperatures resulted in higher creep strains at $265 \mathrm{MPa}(38 \mathrm{ksi})$, which is well below yield and the $349 \mathrm{MPa}(50 \mathrm{ksi})$ prestraining stress. The creep deformation accumulated within the operating temperature range for the ISS (up to $56^{\circ} \mathrm{C}\left(132^{\circ} \mathrm{F}\right)$ ) was negligible, suggesting that creep deformation will not be an issue for Node 1. The creep rates, although initially high, dropped more than five orders of magnitude during the first several hours of the tests at 22 and $56^{\circ} \mathrm{C}\left(72\right.$ and $\left.132^{\circ} \mathrm{F}\right)$, therefore, these tests were terminated. Even at $79^{\circ} \mathrm{C}\left(175^{\circ} \mathrm{F}\right)$, the prestrained 2219-T851 exhibited only a small amount of creep, with a continuously decreasing creep rate throughout the 500 hours test duration. At $265 \mathrm{MPa}$ (38 ksi), only the test conducted at $107^{\circ} \mathrm{C}\left(225^{\circ} \mathrm{F}\right)$ exhibited steady-state and tertiary creep regimes, with the majority of the creep life in the primary creep regime.
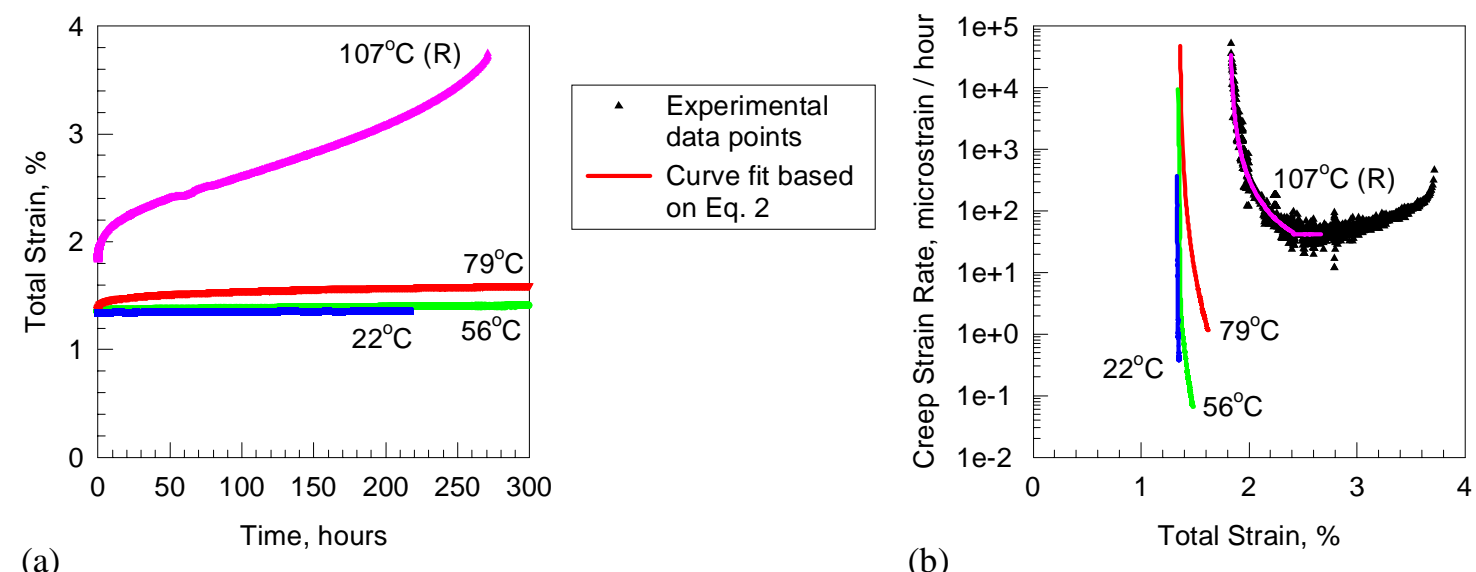

Figure 5. (a) Experimental creep strain data and (b) calculated creep strain rate data (based on Eq. 2) on $2219-\mathrm{T} 851$ at $265 \mathrm{MPa}(38 \mathrm{ksi})$ after $1.5 \%$ prestrain $\left(107^{\circ} \mathrm{C}\left(225^{\circ} \mathrm{F}\right)\right.$ specimen had $2.0 \%$ prestrain).

To examine the effect of prestraining on the creep strength of 2219-T851 in Node 1, several creep tests were conducted with and without prestrain to assess the amount of damage introduced into Node 1 during the proof test. Fig. 6 shows the effect of prestrain on ambient temperature tests conducted at extremely high stress levels (363 MPa (52 ksi), or 98\% of the 2219-T851 ultimate tensile strength), and also includes the final step of the step loaded specimen for comparison. With no prestrain, the 2219-T851 exhibited a continuously decreasing creep rate until rupture at $2.4 \%$ total strain in 0.5 hours. With a prestrain of $1.5 \%$, the creep life was extended from 0.5 hours to 71 hours before rupturing at a total strain of $3.1 \%$ (which includes the residual plastic deformation from prestraining). Prestraining caused strain hardening which increased the creep strength, creep life, and total strain to failure of 2219-T851. In addition, the specimen that received prestraining demonstrated the beginning of transition into steady-state creep before rupturing, as compared to 
the specimen that was not prestrained which demonstrated exclusively primary creep. Regardless of the improved creep life, however, the initial creep rates and the creep rate decay were nearly identical for specimens with and without prestrain.

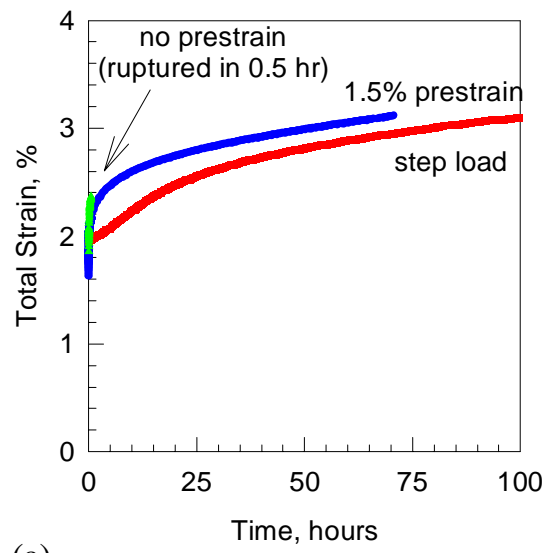

(a)

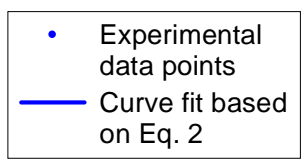

(b)

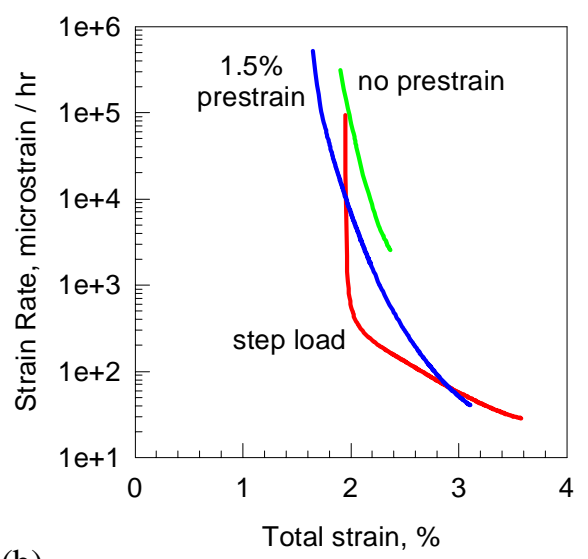

Figure 6. (a) Experimental creep strain data and (b) creep strain rate data (based on Eq. 2) on 2219-T851 at $22^{\circ} \mathrm{C}\left(72^{\circ} \mathrm{F}\right)$ and $363 \mathrm{MPa}(52 \mathrm{ksi})$ with no prestrain, $1.5 \%$ prestrain, and step load.

As indicated earlier, Fig. 6 includes data for the final step in the incrementally loaded specimen shown in Fig. 4. The total strain accumulated in this step loaded specimen prior to rupture was $3.6 \%$, which is greater than the total strain to failure for the room temperature tensile test as well as the other room temperature creep tests, with or without prestrain. Step loading resulted in creep life that was more than double the creep life with $1.5 \%$ prestrain, and nearly 3 orders of magnitude improvement over the specimen without prestrain. Incremental step loading resulted in initial creep rates of similar orders of magnitude at the beginning of each step, and were analogous to the initial creep rates for other creep tests conducted at room temperature and $363 \mathrm{MPa}(52 \mathrm{ksi})$, as can be seen in Fig. 6. However, although the initial creep rates are similar, the creep rate decay is significantly different as a result of the step loading. The step loaded specimen exhibited much sharper decay which then formed a knee as compared to the more gradual decay exhibited by specimens with a single $1.5 \%$ prestraining operation or without any prestrain prior to creep testing.

\section{Conclusions}

1. High stress-moderate temperature conditions result in creep in 2219-T851 that is dominated by primary creep regime.

2. Creep rates were initially very high, but decayed rapidly for all conditions tested.

3. Prestraining caused strain hardening, which increased creep strength, creep life, and total strain to failure.

4. Creep tests resulted in the ability to develop a constitutive equation [1] to predict long term deformation behavior from short term tests. Results suggest that time-dependent deformation should not be an issue at the design stress for ISS.

\section{References}

[1] R. LeMaster \& G. Frady, "International Space Station Node 1 Gusset Elastic-Plastic-Creep Analysis Final Report,” NASA MSFC Report \# 621-026-96-006 (1996).

[2] Annual Book of ATSM Standards, E8-96 (1996), vol. 3.01, pp. 55-96.

[3] L.W. Mayer, Alcoa Green Letter: Alcoa Aluminum Alloy 2219 (1967).

[4] K.M.B. Taminger, et al., "Evaluation of Creep Behavior of Emerging Aluminum Alloys for Supersonic Aircraft Applications,” ICAA-6 proceedings (1998), pp. 1361-1366.

Correspondence may be addressed to Karen Taminger at <k.m.taminger@larc.nasa.gov>. 